The acidic protein fraction obtained from rat liver nuclei contained about 6 per cent arginine and less than $\mathbf{0 . 5}$ per cent phosphorus. No light absorption due to nucleic acids (at $260 \mathrm{~m} \mu$ ) could be detected $\mathrm{n}$ the acidic protein fractions ( $p \mathrm{H} 6$ fractions) from rat liver nuclei, calf thymus 'chromosomes' or boar spermatozoa.

The heads of boar spermatozoa were separated from the tail-midpieces prior to extraction, and it was found that all the protein fractions previously reported ${ }^{4}$ come from the heads.

The location of the acidic protein in the nucleus is not clear. Our present knowledge of the structure of interphase nuclei such as rat liver nuclei does not seem to-warrant any conclusion as to whether or not the extracted material is a part of the chromosomes. Lamb $^{7}$ has interpreted his work on the 'isolated chromosomes' of Mirsky and Ris ${ }^{n}$ as indicating that these thread-like structures are shredded nuclei rather than chromosomes. If Lamb's interpretation is correct, the location of the acidic protein which we have obtained from calf thymus 'chromosomes' is also uncertain.

The spermatozoa of the boar contain a rather large amount of an arginine-rich residue which is insoluble in either sodium chloride or alkali solutions". Recently we have found this residue to be composed entirely of 'ghost' heads. Our work gives some indication that an alkali-insoluble residue may also be present in rat liver nuclei.

\section{TUNG-YUE WANG}

WILLIAM R. KIRKHAM

R. Duncan Daluam

DENNIS T. MAYER

Departments of Biochemistry

Lloyd E. Thomas

\section{and Agricultural Chemistry,} University of Missouri.

1 Mayer, D. T., and Gulick, A., J. Biol. Chem., 146, 433 (1942). -Stedman, E., and Stedman, E., Nature, 152, 267 (1943).

Stedman, E., and Stedman, E., Cold Spring Harbor Symposia on Quantitative Biology, 12, 224 (1947).

4 Thomas, I. E., and Mayer, D. T., Science, 110, 393 (1949).

Dounce, A. L., J. Biol. Chem., 147, 685 (1943).

- Mirsky, A. E., and Ris, H., J. Gen. Physiol., 31, 1 (1947).

' Lamb, W. G. P., Nature, 164, 109 (1949).

\section{Amino-Acids in Posterior Pituitary Protein}

THE protein isolated from the pars neuralis of the pituitary by van Dyke et al. ${ }^{1}$ contains 1 r.U. per $61 \mu \mathrm{gm}$. Pressor, antidiuretic and oxytocic activities are present in constant amounts and in the same ratio found in crude posterior pituitary powder. This protein contains $4 \cdot 3$ per cent sulphur which appeared to be entirely in cystine. It sermed of interest to confirm the earlier conclusion that cystine is the only sulphur-containing amino-acid in the protein and to identify qualitatively as many amino-acids as possible.

$10 \mathrm{mgm}$. of the protein was dissolved in $10 \mathrm{ml}$. of $6 \mathrm{~N}$ hydrochloric acid. After boiling for $20 \mathrm{hr}$. under reflux, the solvent was removed by vacuum. The dry residue was dissolved in $1 \mathrm{ml}$. of 10 per cent isopropanol. A volume of $0.005 \mathrm{ml}$. or a multiple of this volume was used for filter-paper chromatograms. Two-dimensional chromatograms $(0 \cdot 005$ $0.030 \mathrm{ml}$. of hydrolysate) were run with phenol followed by lutedine as well as in reverse order. Sulphur-containing amino-acids were investigated in one-dimensional chromatograms by the platinic iodide reaction; proline and hydroxyproline were

similarly sought by the isatin reaction. Tests for tryptophane were performed without hydrolysing the protein. The results obtained are summarized in the accompanying table.

QUalifative Tests for Amino-Acids in POSTerior Pitutiary

Alanine

Arginine

Aspartic acid

Cysteine

Cystine

Glycine

Hydroxyproline

Isoleucine

The earlier conclusion that all the organically bound sulphur is in cystine was confirmed. Therefore, this amino-acid accounts for about one-sixth of the weight of the protein. Previous work demonstrated that the biological activity of the protein is reduced or abolished by partial or complete reduction of the dithio groups of eystine.

RICHARD J. B
Department of Physiology and Biochemistry, New York Medical College.

H. B. VAN DYKe

Department of Pharmacology,

College of Physicians and Surgeons, Columbia University. Jan. 25.

${ }^{1}$ van Dyke, H. B., Chow, B. F., Greep, R. O., and Rothen, A., J. Pharmacol. Exp. Ther., 74, 190 (1942).

\section{Effects of Iodoacetate on Zymase Fermentation}

THE earlier investigators of iodoacetate poisoning ${ }^{1,2}$ suggested that a phosphorylation process was primarily inhibited; but more recent work $8,4,5$ has attracted attention to the iodoacetate sensitivity of dehydrogenases containing - $\mathrm{SH}$ groups. It is now generally assumed that the first point of attack, when iodoacetate is applied to fermenting yeast, is the stage controlled by the triosephosphate dehydrogenase, while the alcohol dehydrogenase may also be inactivated.

However, even these very sensitive dehydrogenases require concentrations as high as $10^{-3} M$ for strong inhibition in vitro ${ }^{3}$, whereas glucose fermentation, whether by yeast ${ }^{6}$ or by extracted zymase, can be suppressed by concentrations considerably less than $10^{-4} M$. The following observations may be of interest in this connexion.

The fermentation in air of $1 \mathrm{ml}$. aliquots of a 5 per cent zymin preparation from baker's yeast suspended in $M / 15$ phosphate buffer at $p H \mathbf{H} \cdot 0$ provided with manganese ions was slow until glucose or hexosediphosphate was supplied, when a rapid and constant rate of carbon dioxide production was induced. Glucose was added to give a final concentration of $20 \mathrm{mgm} . / \mathrm{ml}$. and hexosediphosphate to $5 \mathrm{mgm} . / \mathrm{ml}$. In the inhibitor experiments appropriate amounts of iodoacetate to give the desired final concentrations were added to selected flasks containing zymin suspension immediately before the addition of substrate. The carbon dioxide outputs of these aliquots were compared with those of control systems.

When the inhibitor was applied in concentrations greater than $10^{-3} M$, fermentation of either glucose or hexosediphosphate was arrested almost completely. In lower concentrations, however, there 